\title{
Development of Guidelines for Low Volume Concrete Road Construction in Sri Lanka
}

\author{
W. K. Mampearachchi and N. A. A. Priyantha
}

\begin{abstract}
The purpose of the study was to develop guidelines for construction of low volume concrete roads in Sri Lanka. A survey was carried out to study current concrete road construction practices and knowledge of the contractors involved in concrete road construction. Survey results show that good practices have not been adopted in low volume road construction in Sri Lanka. The authors have introduced best practices which can be easily adopted by the local road construction industry.

Incorrect joints construction was observed in concrete roads during the site visit and the Authors have introduced a new device for contraction joint construction. A modification to the available method was proposed to measure surface undulation on local concrete pavements and allowable undulation was determined through field investigation. A comparison of various kinds of concrete producing and curing methods and their performance were studied. The authors have evaluated the effectiveness of rebound hammer method which has been used for quality control by some consultants. Rebound hammer reading was compared with compressive strength which was found out from core cutter samples. Double beam vibrator with inbuilt camber was introduced to consolidate and form the camber of the surface layer.
\end{abstract}

Check lists for subgrade / subbase, shoulder, formwork and concrete placing and finishing have been introduced to address weakness and enhance the quality of the pavement construction. Quality and Cost control techniques in the field of low volume concrete road construction in Sri Lanka are also described. Further, the proposed guideline describes the most appropriate methods for preparation of subgrade, subbase and shoulder, and mixing, placing and finishing of concrete.

\section{Introduction}

Concrete has been used for road construction at special locations in the past in Sri Lanka. One of the oldest roads is Chaitya road (marine drive) at Colombo port which used pre tensioned, post tensioned and conventional concrete [5]. Concrete paving has been widely used for low volume roads in Sri Lanka since 2007 as the government allocated funding for local government agencies to construct concrete roads. Low volume roads are normally considered as roads with relatively low traffic volume, an Average Daily Traffic (ADT) of less than 400 vehicles per day. These roads are the tertiary links to the road network and provide access to land and properties

Concrete surfacing is considered as a cost effective road construction technique for low volume roads since concrete roads have less maintenance cost. Currently, few roads managed by the Road Development Authority (RDA), have been constructed using concrete.

\section{Cost Effectiveness of Concrete Roads}

Past research and findings reveal that concrete has added advantages than the asphalt pavements. Some of the early findings have shown that concrete has been a cost effective solution.

Life Cycle Cost Analysis (LCCA) is a forwardlooking decision framework that helps assess

Eng (Dr.) W. K. Mampearachchi, B.Sc. Eng. (Hons) (Moratuwa), MSCE(south Florida), PhD(Florida), CMILT (UK)., MIE(Sri Lanka), Senior Lecturer, Department of Civil Engineering, University of Moratuwa, Sri Lanka.

Eng. N. A. A. Priyantha, B.Sc Eng. (Moratuwa), M.Eng(Highway and Traffic, Moratuwa), MIE(Sri Lanka), Site Engineer, Kumagai Gumi Company, STDP. 
the lifetime costs of a roadway, rather than merely considering the initial construction costs. When LCCA is applied, concrete pavement is, in many cases, less expensive than an asphalt surface of equivalent design [1]. Concrete highways have an excellent track record as a cost-effective investment in the United States. Rigid concrete pavement outperforms flexible asphalt pavement impact on the environment. Nearly 30 percent of U.S. interstate highways are built with concrete [11].

Data from the American Concrete Pavement Association confirms that American states are truly committed to building concrete highways and create competition between the concrete and asphalt paving industries resulting in lower unit costs for both concrete and asphalt highways [8]. This results in more roads being paved for the same cost.

Extensive studies by the National Research Council of Canada[12] confirm previous findings of fuel efficiency of vehicles on concrete roads [13] showing that fully loaded tractor-trailers consume less fuel traveling on concrete pavements than on asphalt pavements over a wide temperature range.

\section{Problem Statement}

ICTAD Standard Specifications for Construction and Maintenance of Roads and Bridges Sri Lanka $[9,10]$ specify some guidelines for concrete road construction. However, most of the details in the specification are related to concrete pavements which are supposed to be constructed using pavers. Still, we have not used pavers for concrete road construction in Sri Lanka and it would not be feasible for low volume roads due to poor road alignments. In the literature review, the Authors have not found any guidelines for low volume concrete road construction.

We have identified the following major issues in the questionnaire survey. Neither pavement thickness nor compressive strength is measured before payments are released to contractors. One of the qualitative parameters of a concrete pavement is roughness. Roughness or surface undulations are measured by standard straight edge and it should be modified to measure surface undulation of local concrete roads. Full depth joints have been seen in local roads and no load transfer between panels. Ineffective curing methods have been used for curing concrete. Concrete transit trucks have been used for concrete mixing. Concrete has not been compacted in certain projects.

The study is focused on development of guidelines for construction of shoulders, subbase, formwork and concrete surfacing based on the condition survey on newly constructed low volume roads in the rural sector.

\section{Concrete Road Condition Survey}

Distressed locations and wrong construction practices have been observed during the site visits.. A survey was done on 24 roads which are located in the Southern Province, to collect concrete road condition data (post construction) and the Authors met the contractors and stakeholders of the surveyed roads to gather their knowledge and experience on concrete road construction. The Authors made a few site visits to concrete road construction sites to observe construction practices.

According to the survey, contraction joint spacing is less than $5 \mathrm{~m}$ in $45 \%$ of the roads and these joints are not straight in $41 \%$ of the roads. Wooden planks have been used to provide contraction joint in $45 \%$ of the roads and these have not been removed in $98 \%$ of such roads. According to the survey results, no camber has been provided in $92 \%$ of the roads. Curing had been done on $70 \%$ of the roads while curing material had been provided for only $4 \%$ of the roads. According to the specifications, instructions had been given to provide a separation membrane between the concrete layer and the sub-base layer, but according to the survey, polythene sheets had been used as a separation membrane only in $25 \%$ of the roads. 


\section{5. Pavement \\ Strength \\ and}

Three concrete core samples were taken from roads as shown in Table 01, using a core cutter machine, and the specified mix proportion of the concrete was 1:2:4 (cement : sand : aggregate) . Thickness and strength of the samples are shown in Table 01. Design strength of 1:2:4 concrete is $15 \mathrm{~N} / \mathrm{mm}^{2}$ and according to Table 01 specified design strength was achieved only at Wadihitiniwasa road. Specified pavement thickness was $150 \mathrm{~mm}$ and that has not been maintained even in a single case.

Core samples were tested from sites where concrete mixing had been done by concrete transit trucks. It has been observed, during site visits that the concrete discharged from transit trucks was not properly mixed as transit trucks are designed for concrete transportation only. Arrangement of blades inside the rotating drum of a concrete transit truck and a concrete mixer was studied. Visual observations have also proved that concrete transit trucks are not suitable for mixing concrete. Furthermore, rebound hammer tests were also carried out on some roads. In addition to that, a few rebound hammer tests were carried out on concrete roads which have been constructed using concrete mixers. Standard deviation of pavement strength was calculated in both cases and a comparatively high standard deviation on roads constructed by using concrete transit was not trucks. All these facts prove that concrete transit trucks are not suitable for mixing concrete.

The paving thickness was less than that specified. The core sample which satisfied the strength requirement has the lowest thickness. It was found that the payment was released based on the hammer reading and the strength was compensated by the thickness to get approval from the authorities.
Table 1 - Core sample strength.

\begin{tabular}{|c|l|c|c|}
\hline No & \multicolumn{1}{|c|}{ Location } & Thickness & $\begin{array}{c}\text { Strength } \\
\mathrm{N} / \mathrm{mm}^{2}\end{array}$ \\
\hline 01 & $\begin{array}{l}\text { Beligaswatta } \\
\text { Kohilawala Para }\end{array}$ & $140 \mathrm{~mm}$ & 9.96 \\
\hline 02 & $\begin{array}{l}\text { Wadihitiniwasa } \\
\text { Para, Beliatta }\end{array}$ & $95 \mathrm{~mm}$ & 16.45 \\
\hline 03 & $\begin{array}{l}\text { Dewana Piwisum } \\
\text { Para, Ihalabeligalla }\end{array}$ & $140 \mathrm{~mm}$ & 10.76 \\
\hline
\end{tabular}

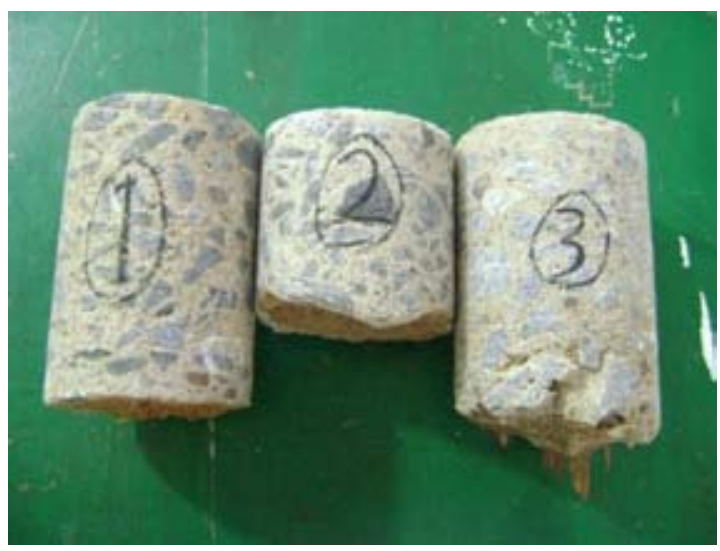

Figure 1- Concrete core samples

Rebound hammer can be used to measure surface hardness of concrete pavements where surface hardness correlates with strength of the pavement. However, surface hardness depends on various factors such as moisture condition of surface, aggregate size etc (BS 4408:PART 4) [6] It is advisable to use hammer test as a field test for quality control since it is possible to test the overall pavement. However, core sample testing should be conducted for quality assurance to verify the hammer results (strength) and the pavement thickness.

\section{Effectiveness of Curing Material}

Low rich concrete is being used for local road concrete pavements and according to Sammir et..al, curing should be done for at least 7 days for such concrete.[7]

Saw dust was used as water retaining material at Napekanda road while coir dust was used at Beligaswatta road since these materials were 
freely available. Sandy soil can also be used as a water retaining material.

Effectiveness of curing depends on water retaining ability of such materials, and in order to compare the effectiveness of different materials, an experiment was conducted on a dry sunny day (maximum temp of $35^{\circ} \mathrm{C}$ ). One meter by one meter rectangles were marked on the selected pavement.. After that $27000 \mathrm{~cm}^{3}$ of measured coir dust was spread evenly on the first block and the same volume of sandy soil was spread on the second block while keeping the third block as a control surface. Water was spread on the coir dust, sandy soil and control section to saturated conditions at 6:30 am. Intervals at which water was spread on the control section (without a curing material) to keep it in a wet condition are given in Table 2. It was found that coir dust and sandy soil sections remained in a wet condition during the study period. Results show that water spraying is required in 1 hour intervals in morning and evenings and in 30 minute intervals during mid day for curing concrete without a water retaining material. It can be concluded that it is essential to use a water retaining material for effective curing of road sections.

Table 2- Water retaining material testing data.

\begin{tabular}{|c|c|c|c|c|}
\hline Time & $\begin{array}{c}\text { Time } \\
\text { deference } \\
\text { (Minutes) }\end{array}$ & $\begin{array}{c}\text { Slab } \\
\text { without } \\
\text { material }\end{array}$ & $\begin{array}{l}\text { Coir } \\
\text { dust }\end{array}$ & $\begin{array}{c}\text { Sandy } \\
\text { soil }\end{array}$ \\
\hline $6: 30$ & & $\sqrt{ }$ & $\sqrt{ }$ & $\sqrt{ }$ \\
\hline $7: 30$ & 60 & $\sqrt{ }$ & $x$ & $x$ \\
\hline $8: 50$ & 80 & $\sqrt{ }$ & $x$ & $x$ \\
\hline $9: 55$ & 65 & $\sqrt{ }$ & $x$ & $x$ \\
\hline $10: 45$ & 50 & $\sqrt{ }$ & $x$ & $x$ \\
\hline $11: 20$ & 35 & $\sqrt{ }$ & $x$ & $x$ \\
\hline $11: 55$ & 35 & $\sqrt{ }$ & $x$ & $x$ \\
\hline $12: 50$ & 55 & $\sqrt{ }$ & $x$ & $x$ \\
\hline $13: 42$ & 52 & $\sqrt{ }$ & $x$ & $x$ \\
\hline $14: 33$ & 51 & $\sqrt{ }$ & $x$ & $x$ \\
\hline $15: 30$ & 57 & $\sqrt{ }$ & $x$ & $x$ \\
\hline $16: 30$ & 60 & $\sqrt{ }$ & $x$ & $x$ \\
\hline
\end{tabular}

Note: $-(\sqrt{ })$ Water spread $(\times)$ water not spread

\section{Measuring Surface Undulation}

With reference to the available specification, surface undulation of a concrete pavement shall be evaluated by a standard $3 \mathrm{~m}$ straight edge, but if there is a camber, this length cannot be used to measure undulations of concrete roads, because the average width of local roads is about $3 \mathrm{~m}$. In this case, the standard straight edge was modified to evaluate undulations in low volume concrete pavements in Sri Lanka.

An aluminum rectangular hollow box of $1.5 \mathrm{~m}$ length, $50 \mathrm{~mm}$ height and $25 \mathrm{~mm}$ width was used as the modified straight edge. The length of the selected straight edge was $1.5 \mathrm{~m}$ since half width of most concrete roads is about 1.5 $\mathrm{m}$. Two supports of height $20 \mathrm{~mm}$ were fixed at the ends of the straight edge. A wedge which is used to measure the space between the concrete surface and straight edge was prepared from a steel plate with a handle. The length of the wedge was $350 \mathrm{~mm}$ and height 50 $\mathrm{mm}$ as shown in figure 02 .

Surface undulations were measured in selected roads in the Galle district after the field survey. Table 3 shows the data collected from Kahaduwa Milidduwa road in Galle. This road has been rated as a good surfaced road in the survey. It can be seen that undulations exceeded $10 \mathrm{~mm}$ only at three locations. This study shows that $10 \mathrm{~mm}$ of undulation can be allowed for rural road construction and it can be achieved with available resources.

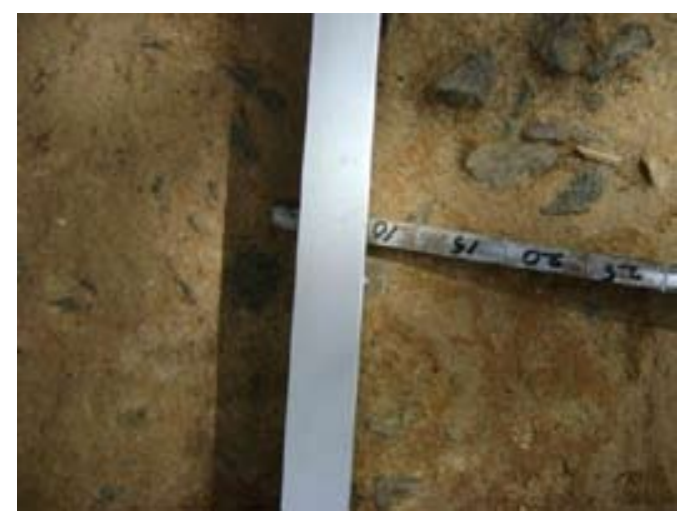

Figure 2 - Modified straight edge 


\section{Construction of Joints}

Shrinkage stresses are induced in concrete pavement with the hydration of cement and shrinkage continues for a long period. As a result of these stresses irregular cracks can be induced in concrete. These cracks can be avoided by providing partial depth joints at 4$5 \mathrm{~m}$ intervals so that cracks due to stress are developed under the formed joint. The joint requires only a saw cut upto $1 / 3$ of the pavement thickness. All the joints observed during the survey were full depth joints (wooden plank placed to separate slabs). Full depth contraction joints are weak in load transfer between slabs and an experiment was carried out to construct half depth contraction joints at Napekanda road by adopting special procedures.

The location for a contraction joint was identified and a $14 \mathrm{~mm}$ wide groove was prepared on both sides of the formwork upto half of its depth as shown in figure 03 . Thereafter, the plywood was covered with a polythene sheet, as shown, and was inserted into the groove. The objective of covering the plywood with a polythene sheet was to prevent concrete sticking to the plywood. Concrete was then poured into both sides of the joint. The plywood plank was then removed, slowly, about 4 hours after pouring of concrete leaving the polythene sheet with the concrete. This joint construction method has been further developed by limiting the joint width to $6 \mathrm{~mm}$ using a perspex sheet instead of the plywood plank. Mould oil can be used instead of a polythene sheet to prevent sticking of concrete to the Perspex sheet. Figure 4 shows the contraction joint construction mechanism developed by the University of Moratuwa.

Table 3 - Reading of surface undulations

\begin{tabular}{|c|c|c|c|c|}
\hline 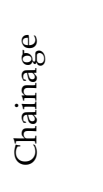 & 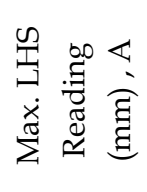 & 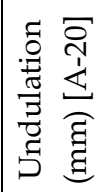 & 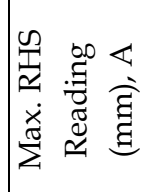 & 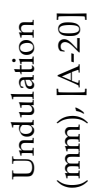 \\
\hline+000 & 22 & 2 & 25 & 5 \\
\hline+020 & 27 & 7 & 25 & 5 \\
\hline
\end{tabular}

\begin{tabular}{|r|c|c|c|c|}
\hline+040 & 30 & 10 & 30 & 10 \\
\hline+060 & 40 & 20 & 15 & -5 \\
\hline+080 & 30 & 10 & 20 & 0 \\
\hline+100 & 20 & 0 & 22 & 2 \\
\hline+120 & 20 & 0 & 26 & 6 \\
\hline+140 & 27 & 7 & 32 & 12 \\
\hline+160 & 28 & 8 & 33 & 13 \\
\hline+180 & 30 & 10 & 24 & 4 \\
\hline Average & & 7.4 & & 5.2 \\
\hline SD & & 5.37 & & 5.2 \\
\hline & & \\
\hline
\end{tabular}

Figure 3 -Construction of half depth contraction joint

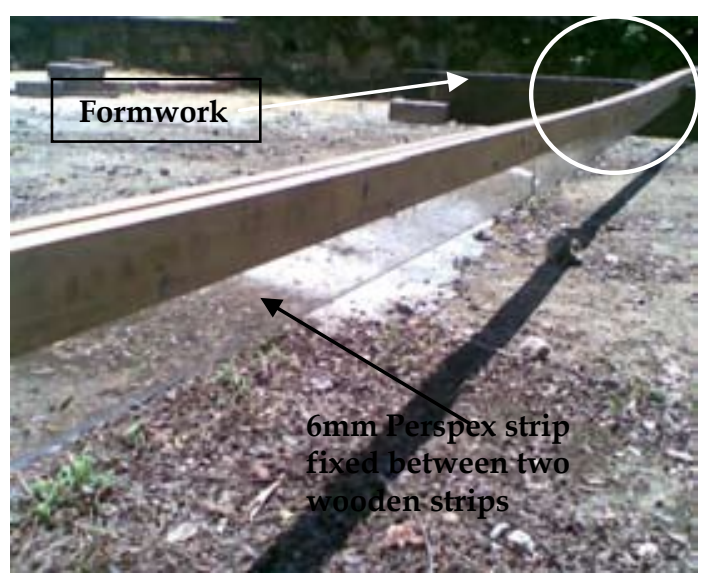

Figure 4 -Contraction joint making device developed by University of Moratuwa

Furthermore, a few half depth contraction joints were constructed at Aduranwila Ehalagedara Para, Poddala, Galle by the Authors. The construction process of the half depth joints was different from that of Napekanda because a Styrofoam sheet of $50 \mathrm{~mm}$ width was used while total thickness of the pavement was $100 \mathrm{~mm}$. The Styrofoam sheet was removed on the day following concreting..

If concrete paving is done without providing joints, cracks will form naturally [3] and this was observed during the condition survey. Also. it was found that natural cracks had 
developed on 7 roads out of 24 which have not been provided with contraction joints. The average spacing of these natural cracks was 12 $\mathrm{m}$.

\section{Camber/Transverse Slope.}

According to Vazirani et..al[14], camber for concrete pavements should be kept between $1.7 \%$ and $2 \%$. According to guidelines provided to contractors, requirement of a camber or transverse slope has not been mentioned. As a result, camber was not provided on $92 \%$ of the concrete roads. Construction of camber is not difficult and 2\% camber was achieved at Napekanda road without much effort. It is essential to have a camber in the road surface for surface water runoff and also for each layer below (drain out infiltrated water to side drains) and should be included in the guidelines.

\section{Compaction of Concrete}

It was found, in the survey, that concrete was not compacted using a vibrator when placed. It is not advisable to use a poker vibrator for compaction of thin concrete layers. The Authors have developed a double beam surface vibrator with an inbuilt camber $(2 \%)$ to compact thin concrete layers used in low volume road construction. Vibration was created by placing a $1 \mathrm{hp}$ motor with an eccentric weight at the center. Figure 5 shows the double beam vibrator for compaction of concrete. It is made of hollow aluminum sections with a steel channel for the camber. Two handles located at the ends can be used to move the vibrator forward over the formwork. Forward speed is critical in the correct use of the vibrating beam and should be limited to between 0.5 and $1.0 \mathrm{~m} / \mathrm{min}$. The lower speed should be used for thicker slabs. A second pass at a faster speed may be made for better finishing.

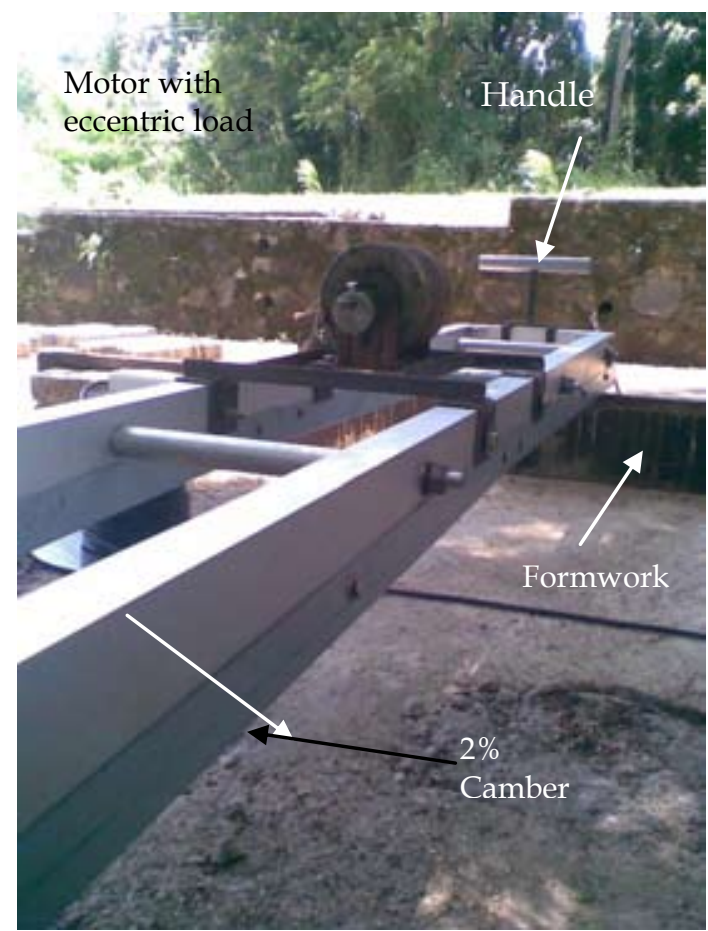

Figure 5 -Double beam surface vibrators

\section{Other Considerations}

The recommended slump for concrete pavements, in India, is $25 \mathrm{~mm}$ to $50 \mathrm{~mm}$, if paving is done by pavers [14]. The slump was measured during construction of Aduranwila Ehalagedara road and it was between $75 \mathrm{~mm}$ and $125 \mathrm{~mm}$. Literature shows that a slump of 50- $100 \mathrm{~mm}$ is sufficient for placing concrete. However, excessive slump should not be allowed since it will lead to using more free water for concrete preparation. Close supervision is required at the paving site to ensure quality of concrete.

Permanent marks on the pavements were observed on $50 \%$ of roads due to their premature use. Access to pedestrians, vehicles or animals should not be allowed before concrete has gained sufficient strength in order to avoid permanent marks. Barricades are suggested as a solution for this purpose. During the site visit at Agunukolapalassa, structural damage of the pavement was observed due to heavy vehicle movements before gaining sufficient strength and these damages are more critical than permanent marks. 
The shoulder provides space for pedestrians and additional space for traffic. Shoulders can be constructed either before or after placing concrete. Construction of shoulder before placing concrete is the better practice. Shoulder construction should be delayed until the concrete gains sufficient strength in the event of construction of the shoulder after placing concrete.

Side drains for disposal of storm water should be constructed and maintained to increase the lifespan of the pavement. It was observed that proper drainage has not been constructed in the roads selected for the survey.

\section{Conclusions and Recommendations}

Design weaknesses and poor construction practices were observed during the condition survey. Summary of good practices to overcome design and construction weaknesses are given below.

1. One third to half depth contraction joint should be provided at $4-5 \mathrm{~m}$ intervals using $6 \mathrm{~mm}$ to $12 \mathrm{~mm}$ wide plywood planks. A device developed by the University of Moratuwa with a $6 \mathrm{~mm}$ perspex sheet is recommended to make the contraction joints.

2. According to the survey, concrete was cured on $70 \%$ of the roads and effectiveness of curing can be enhanced with coir dust, saw dust or sandy soil as water retaining material.

3. The use of concrete transit trucks which are designed for transporting concrete, for mixing of concrete should be discouraged. As a result of poor mixing of concrete, in transit trucks, concrete strength is lowered and leads to a low quality product.

4. Roughness or surface undulation affects travel comfort of vehicle occupants. A straight edge of $1.5 \mathrm{~m}$ long, is specified for controlling undulations of concrete surface and test results show that undulations of $10 \mathrm{~mm}$ or less for $1.5 \mathrm{~m}$ straight edge provide a good surface for low volume concrete roads.
5. Compaction of concrete using surface vibrators has not been done in low volume concrete road construction. It is recommended to use double beam vibrators developed by the University of Moratuwa to consolidate and form the surface cross fall of concrete roads.

6. Load bearing capacity of a concrete pavement is related to its thickness and compressive strength. Thickness of the pavement after construction is not easily obtained and core cutter should be used to extract samples. Extracted samples can be used to measure concrete thickness and test for compressive strength. Compressive strength and the thickness of the random samples should be evaluated before releasing payments to the contractor.

Weaknesses in current construction practices were identified during site visits and through interviews with personnel involved in construction, maintenance and administration of concrete roads. Check lists were developed to include the good practices and to enhance quality of low volume concrete roads as given in the Appendix. Contractors should use the check list, and work under each item should be certified by the consultant or the project management unit of the project before moving to the next item.

\section{References}

1. American Concrete Pavement Association, Life Cycle Cost Analysis: A Guide for Comparing Alternate Pavement Analysis, EB 2002, 220P.

2. Design and Construction of Joints for Concrete Streets, Concrete Information, American Concrete Pavement Association, IS061.01P.(ACPA 1992), 1992.

3. Guruchandran, Singh \& Jagdish Singh, Highway Engineering, Standard Publication Distributors Delhi, Fifth Edition, 2008. 
4. Kadyali, L. R., \& Lal, N. B., Principles and Practice of Highway Engineering, Khanna Publishers, Delhi -6 fifth edition, 2008.

5. Kulasinghe, A.N.S., Construction of Marine Drive in Colombo including Sea Walls, New Lighthouse and Concrete Roadway in Prestressed concrete.1951, http://kulasinghe.com/shells.htm

6. WSDOT, Rebound Hammer Determination of Compressive Strength of Herded Concrete, WSDOT Material Manual, M4601.03, January 2009.

7. Samir, H, AL Ani and Mokdad, A. K. AL Zaiwary(1988) The Effect of Curing Period and Curing Delays on Concrete inHhot Weather, Building Material Development, Building Research Center Bagdad, Iraq 2005-212.

8. Southeast Chapter American Concrete Pavement Association, "Who says..."Concrete Pavement Costs Too Much?" Count on Concrete Pavement, 2005.

9. Standard Specifications for Construction and Maintenance of Roads and Bridges, Institute for Construction Training and Development, Sri Lanka, Revised Draft Document 2005.(SSCM 2005).

10. Southern Transport Development Project, Highway Section Kurudugahahetekma to Matara. Volume 3-Technical specification 2001(STDP 2001)

11. US Department of Transportation Federal Highways Administration web site, Office of Highway Policy Information, Highway Statistics 2005. http://www.fhwa.dot.gov/policy/ohim/ $\underline{\mathrm{hs} 05 / \mathrm{xls} / \mathrm{hm} 12 . \mathrm{xls}}$

12. Taylor, G.W., Patten, J.D., Effects of Pavement Structure on Vehicle Fuel Consumption - Phase III, prepared for Natural Resources Canada Action Plan
2000 on Climate Change and Cement Association of Canada, January 2006.

13. Taylor, G.W., Dr. Farrell, P., and Woodside A., Additional Analysis of the Effect of Pavement Structure on Truck Fuel Consumption, prepared for Government of Canada Action Plan 2000 on Climate Change, Concrete Roads Advisory Committee, August 2002.

14. Vazirani, V. N., \& Chandola, S. P., Concise handbook of Civil Engineering, S Chand and Company LTD, New Delhi, revised edition 2008. 


\section{Appendix}

Road name:-

Checked By:-

Date:-
Chainage:-

Designation:-

(All items to be checked in 'Done' column. NA if not applicable)

A. Check List for Sub Base/ Shoulders

\begin{tabular}{|c|l|c|}
\hline No & \multicolumn{1}{|c|}{ Description } & Done \\
\hline 1 & Is available soil, Granular material, borrow material approved & \\
\hline 2 & Is material free from debris or any other ingredient that may deteriorate & \\
\hline 3 & Is the sub base on stable firm ground? & \\
\hline 4 & Is borrow material from approved borrow areas? & \\
\hline 5 & Is plant adequate for on site operations & \\
\hline 6 & Is the area of work set out? & \\
\hline 7 & Is previous layer approved? & \\
\hline 8 & Is each layer parallel to the final sub base layer & \\
\hline 9 & Is compaction plant approved & \\
\hline 10 & Has a compaction trial been undertaken & \\
\hline
\end{tabular}

\section{B.Check List for Form Work}

\begin{tabular}{|l|l|c|}
\hline No & \multicolumn{1}{|c|}{ Description } & Done \\
\hline & Is vertical alignment as specified? & \\
\hline & Is horizontal alignment as specified? & \\
\hline & Are dimensions as per specification? & \\
\hline & Are Supports as per requirement? & \\
\hline & Are Quality and thickness of shutters as per specification? & \\
\hline & Are Quality and location of supports as per requirement? & \\
\hline
\end{tabular}

\section{Check List for Concrete Placing}

\begin{tabular}{|c|c|c|c|}
\hline \multicolumn{2}{|c|}{ No } & Description & Done \\
\hline 1 & \multirow{14}{*}{$\begin{array}{l}\text { Before } \\
\text { concreting }\end{array}$} & Has the method of construction been approved & \\
\hline 2 & & $\begin{array}{l}\text { Is formwork alignment, dimensions, rigidness \& surface cleanliness } \\
\text { sufficient? }\end{array}$ & \\
\hline 3 & & Are Joints between formwork closed (no gaps) ? & \\
\hline 4 & & $\begin{array}{l}\text { Are extraneous material removed from the forms immediately before } \\
\text { placing concrete? }\end{array}$ & \\
\hline 5 & & Are Forms treated with approved oil? & \\
\hline 6 & & Is sub base surface with the required moisture content? & \\
\hline 7 & & Is the sub base surface undulation at approved level? & \\
\hline 8 & & Mixing and compaction machines as required and in good condition? & \\
\hline 9 & & Are sand, metal and cement at required specification? & \\
\hline 10 & & Is material measuring method at acceptable level? & \\
\hline 11 & & Is concrete hauling method at acceptable level? & \\
\hline 12 & & Are surface leveling tool and booming tool available? & \\
\hline 13 & & Are covering sheets available if it rains? & \\
\hline 14 & & Is slump cone and test mould available? & \\
\hline 15 & \multirow{3}{*}{$\begin{array}{l}\text { During } \\
\text { concreting }\end{array}$} & Is concrete placed without segregation? & \\
\hline 16 & & Is concrete compacted well? & \\
\hline 17 & & $\begin{array}{l}\text { Are the final surface level, thickness and undulation at acceptable } \\
\text { levels? }\end{array}$ & \\
\hline 18 & \multirow{3}{*}{$\begin{array}{l}\text { After } \\
\text { concreting }\end{array}$} & Does the road close for traffic satisfactorily? & \\
\hline 19 & & Is Water retaining material (core dust) available at site ? & \\
\hline 20 & & Is concrete being curing satisfactorily for minimum of 7 days? & \\
\hline
\end{tabular}

Remarks

Date

Signature 
